\title{
Association of High w-6/w-3 Fatty Acid Ratio Diet with Causes of Death Due to Noncommunicable Diseases Among Urban Decedents in north India
}

\author{
Jan Fedacko ${ }^{1}$, Viola Vargova ${ }^{1}$, Ram B. Singh ${ }^{2},{ }^{*}$ Baby Anjum ${ }^{3}$, Toru Takahashi ${ }^{4}$, Miki Tongnuka ${ }^{5}$ \\ Suniti Dharwadkar ${ }^{6}$, Surendra Singh ${ }^{7}$, Vijendra Singh ${ }^{7}$, Shallendra K. Kulshresth ${ }^{7}$, \\ Fabien De Meester ${ }^{8}$ and Douglas W. Wilson ${ }^{9}$
}

\author{
${ }^{1}$ Safaric University, Kosice, Slovakia \\ ${ }^{2}$ Halberg Hospital and Research Institute, Moradabad, India \\ ${ }^{3}$ Departments of Biochemistry, C S M Medical University-Lucknow, India \\ ${ }^{4}$ Graduate School of Human Environment Science, Fukuoka Women's University, Japan \\ ${ }^{5}$ Department of Nutrition and Health Sciences, Fukuoka Women's University, Fukuoka, Japan \\ ${ }^{6}$ S.B. College of Science, Aurangabad, India \\ ${ }^{7}$ Hindu College, Moradabad, India \\ ${ }^{8}$ Tsim Tsoum Institute, Krakow, Poland \\ ${ }^{9}$ School of Medicine and Health, Durham, UK
}

\begin{abstract}
Introduction: There is evidence that the Western type of diet has adverse effects, and prudent dietary patterns may have beneficial effects against deaths from cardiovascular and other chronic diseases. In the present study, we examine the association of dietary patterns with causes of deaths among urban decedents in north India.
\end{abstract}

Subjects and Methods: Randomly selected records of death of 2222 (1385 men and 837 women) decedents, aged 25-64 years, were examined. Clinical data and causes of death were assessed by a questionnaire based on available hospital records and a modified WHO verbal autopsy questionnaire. Dietary intakes of the dead individuals were estimated by finding out the food intake of the spouse from 3-day dietary diaries and by asking probing questions about differences in food intake by the decedents.

Results: The score for intake of prudent foods was significantly greater and the ratio of w-6/w-3 fatty acids of the diet significantly lower for deaths due to 'injury' and accidental causes compared to deaths due to non-communicable diseases (NCD). Multivariate logistic regression analysis revealed that after adjustment for age, total prudent foods (OR,CI: $1.11 ; 1.06-1.18 \mathrm{men} ; 109 ; 1.04-1.16$ women) as well as fruits, vegetables, legumes and nuts (1.07; 1.02-1.12 men; $1.05 ; 1.99-1.11$ women) were independently, inversely associated whereas Western type foods $(1.02 ; 0.95-1.09$ men; 1.00 ; 0.94-1.06 women); meat and eggs(1.00-0.94-1.06 men; 0.98; 0.93-1.04 women) and refined carbohydrates $(0.98 ; 0.91-1.05$ men, $0.95 ; 0.89-1.02$ women $)$ and high w-6/w-3 ratio of fatty acids were positively associated with deaths due to NCDs.

Conclusions: Increased intake of high w-6/w-3 ratio Western type foods and decline in prudent foods intake may be a risk factor for deaths due to NCDs.

Keywords: Mortality, nutrition, disease, sudden death, stroke, infections, cancer.

\section{INTRODUCTION}

The United Nations, High-Level Meeting (UN HLM) was held on Non-communicable Diseases (NCDs) in September, 2011, in recognition of the global threat of these

*Address correspondence to this author at the Halberg Hospital and Research Institute, Civil Lines, Moradabad (UP), India; Tel/Fax: 0091 5912417437;

E-mail: rbs@tsimtsoum.net problems [1], mainly heart disease and stroke, cancer, diabetes, and chronic respiratory diseases. The meeting was attended by the world's Heads of States and governments, creating a unique opportunity to advance globally the prevention and treatment of NCDs. Increased intake of energy characterized with dietary fatty acids; trans fat, w-6 fat, saturated fat and refined carbohydrates, in conjunction with physical inactivity and family history are important risk factors of obesity [1-6]. Western diet and lifestyle are known 
to enhance the risk of NCDs; coronary artery disease (CAD), sudden cardiac death (SCD), hypertension, diabetes, insulin resistance, stroke and cancer [3-9]. The risk of death from cardiovascular diseases (CVD), diabetes and cancer increases when people become rich and obese which in part may be due to dietary alterations [2-9]. The present Western diet appears to be deficient in omega-3 fatty acids and a ratio of omega- 6 to omega- 3 of 15-50/1 has been observed among various populations, instead of $1 / 1$ as is the case with wild animals and presumably human beings (Table 4) [8-13]. Omega-3 fatty acids may be alpha linolenic acid (ALA) which is rich in plant foods as well as eicosapentaenoic acid(EPA) and docosahexaenoic acid(DHA) found in fish and marine foods. Most children were given cod-liver oil before 1940s, as a source of vitamin A and vitamin D, which is rich in w-3 fatty acids. The consumption of cod-liver oil was drastically decreased, when these vitamins were available from synthetic source, contributing further to the decrease of EPA and DHA intake by the modern communities. Thus an absolute and relative increase of omega-6/omega-3 fatty acid ratio in the food supply of Western societies has occurred after 1910 with industrialization and urbanization. It is known that during evolution, omega-3 fatty acids were found in all foods consumed; meat, wild plants, eggs, fish, nuts and berries [8-10]. Experimental studies on wild animals confirm the original observations of previous researchers; Crawford et al., about the validity of high $\mathrm{w}-3$ fatty acids in the evolutionary foods [11-13]. However, rapid dietary changes over short periods of time as have occurred over the past 100 years, is a totally new phenomenon in human evolution resulting in marked increase in the consumption of modern foods deficient in antioxidant nutrients, w-3 fatty acids and essential and non-essential amino acids [2-16] (Table 5).

Recently, dietary patterns have been proposed to be important in the pathogenesis of chronic diseases and allcause mortality which appears to be due to proinflammatory effects of Western diet [8-17]. According to prospective cohort studies [18-24], dietary patterns consisting of high intakes of vegetables, fruits, legumes, fish, poultry, and whole grains, can be protective against mortality from cardiovascular and malignant diseases [11]. These findings are in parallel with the outcomes of several epidemiological studies, reporting inverse relationships between consumption of fruits and vegetables and the incidence of coronary artery disease (CAD) [17-24]. However, in these studies, the role of w-6/w-3 fatty acids has not been highlighted. The UN HLM concluded that NCDs are a global challenge which occur due to poverty as well as they also cause and entrench poverty, and are a threat to human, social, and economic development [1]. However, their approach to NCDs appears to be restrictive because only salt, tobacco, alcoholism, sedentary behavior and poverty are considered major risk factors, without any consideration of $\mathrm{w}-6 / \mathrm{w}-3$ ratio of the fatty acids of diets and poor health promotion policies [1]. The burden of death and disability attributable to NCDs is rising in all lower and upper middle- and high-income countries, because of the rapid changes in the diet and lifestyle patterns [7, 1524]. Millions of deaths occur every year due to poverty as suggested in UN HLM, which appear to be due to lack of health education and poor health policies adopted in these countries. The $36 \cdot 1$ million deaths per year as a result of NCDs represent almost two of three deaths per year worldwide [7]. Of these deaths, 22.4 million arise in the poorest countries, and 13.7 million in high-income and upper-middle-income countries. CVD are number one causes of death globally and are projected to remain the leading cause of death [7]. In the present study, we examined the association of high w-6/w-3 ratio of food consumption patterns with causes of death among urban decedents in north India.

\section{MATERIAL AND METHODS}

The population of the Moradabad city which is situated in north India, is 0.641 million residing in 306 streets or 60 wards based on the 2001 census. All the deaths that occurred in the city of Moradabad may be verified in the birth and death record section of municipal board office [25-27]. Religious considerations do not allow us to conduct autopsy to find out the exact causes of death. Therefore, records available at the Municipal Board might not be correct. These records are based on certificates issued by the doctors based on clinical diagnosis and laboratory examinations.

We studied the records of randomly selected, 2842 adult victims, aged 25-64 years, of which 2222 victim's relatives, could respond for this study, during the last two years, July1999 to July 2001 [25-27]. Of 2222 victims, 1385 were males and 837 were females. All the families of these 2222 victims were contacted individually to find out the causes of deaths by verbal autopsy questionnaire [25-27]. In developing countries due to religious considerations, autopsies are difficult and the causes of death are obtained by detailed questionnaires administered to spouse and the doctors involved. The head of every family was personally called after communication with the help of the local accessible doctor in the street. At least three calls, via letter/telephone and personal contact via lane doctor were made before any subject or family was declared a non-contact or non-replier; one in the morning, one in the evening, around $17.00 \mathrm{hrs}$. and the last one at the weekend.

The survey team included, a scientist, a health worker and a doctor, who were trained and briefed regarding the details of the questionnaire before starting the survey. The case record form was pre-tested by the concerned committee in roughly 30 to 60 families. It was found that $10 \%$ of the families who came within reach of survey were declared non-contact or non-responder as observed in another survey. Detailed interviews were possible among $90 \%$ of the families approached. Clinical data on age, sex, height, weight, marital status, occupation, education, past and family history, history of hypertension, diabetes, stroke, heart attack, kidney disease, liver disease, alcohol intake, drug intake, tobacco intake, lung tuberculosis, bronchitis, asthma, cancer, mental diseases, diarrhea and dysentery, and brain, CVD, infectious diseases, malaria, dengue and accidents, etc, were recorded based on medical record of the victim, death certificate issued by the doctor, interview of the doctor and the family doctor, interview of the spouse and other family members, with the help of a pretested questionnaire, to know the cause of death. Family doctor or spouses of the victim were asked to suggest a person with identical age, sex, height and weight as that of the victim. In those medical records, in 
which data on height and weight were not available, we collected these data from these matching subjects. Subjects were classified according to BMI into underweight (BMI $<18.5)$, normal weight $\left(18.5-22.9 \mathrm{~kg} / \mathrm{m}^{2}\right)$, overweight $(23$ $\left.24.9 \mathrm{~kg} / \mathrm{m}^{2}\right)$, and obese $\left(25-29.9 \mathrm{~kg} / \mathrm{m}^{2}\right)$ and obesity $(>30 \mathrm{~kg} /$ $\mathrm{m}^{2}$ ) [26]. The socio- economic status (SES) of the family was classified based on attributes of housing condition, education, occupation, per capita income and ownership of consumer durables like car, television, automobiles, etc in the household [27]. Per capita income was calculated by dividing the total income of the family, by the number of family members. The diagnosis of risk factors was based on available records, inquiry from the spouse and doctors involved.

\section{Dietary Autopsy}

Dietary intakes of the victim were obtained by trained interviewers by finding out the food intake of the spouse by using 3-day dietary diaries and filling of questionnaires, by asking probing questions about differences in food intake by the decedents. Food models, food measures and food portions were used by the dietitian to find out the exact food intakes of the victims. Nutrient intakes were calculated with the help of Indian food composition tables and other sources [28].

Dietary intakes were also assessed with the use of a validated food frequency questionnaire that includes approximately 62 foods and beverages commonly consumed in India [25-28]. Standard portion sizes were used for the estimation of consumed quantities, and nutrient were calculated by using a food composition database modified to accommodate the particularities of the Indian diet. For each participant, grams per day of intake of various food groups and nutrients, as well as total energy intake, were calculated.

For this analysis, we focused on nine nutritional variables: fruits, vegetables, legumes, and nuts, milk and curd, cereals, meat and eggs. Salt intakes were assessed by finding out the amount of salt mixed in the food divided by the number of family members and then adding salt consumed by each member during eating.

\section{Indo-Mediterranean Diet Score}

The traditional Indian diet is rich in legumes, seasonal vegetables, wheat and rice and if it is enriched with seasonal vegetables, fruits and nuts, it may be called IndoMediterranean diet. The conformity of the traditional Indian diet was studied with a 10 -unit scale. The scale relies on 8 dietary components that capture the essence of the traditional Indian diet. Fruits, vegetables, legumes and nuts, cereals, tubers, milk and curd and mustard oil that are presumed to be beneficial for health, whereas Western type foods, such as bread, meat and eggs and butter, clarified butter, w- 6 rich oils, sugar and salt are presumed not to be beneficial. We assigned values of 0 or 1 to each of the above indicated components, using the sex-specific medians in the studied population as cut-offs. We assigned a value of 0 to people whose consumption was below the median values of components with a presumably beneficial effect and a value of 1 to people with consumption equal to or above the median. In contrast, we assigned a value of 1 to people with below the median consumption of components without a beneficial effect and a value of 0 to those whose consumption of these components was above the corresponding median. Thus, the total diet score can take values from 0 (minimal conformity to the IndoMediterranean diet) to 9 (maximal conformity to the IndoMediterranean diet).

\section{STATISTICAL ANALYSIS}

We used the chi-square test for the comparison of frequencies in the two groups. Only $\mathrm{P}$ values $<0.05$ and the two tailed t-test were considered significant to ascertain level of significance. A relation was determined between two measured quantities of food intakes and causes of deaths and the significance of any trend was calculated using Kendall's $\tau$ rank correlation coefficient. It is used to test the strength of a relationship between the two measured quantities such as measured quantities of two different type of food intakes and causes of deaths. Simply it is a non-parametric hypothesis test that measures rank correlation that is similarly to the ordering of data when ranked by each of the quantities.

\section{RESULTS}

The results for sex and associated clinical data, based on the records and by verbal autopsy questionnaire, among 2222 victims (1385 males and 837 females), aged 25-64 years, dying due to various causes, are given in the Table 1. The mean age, $(42.12 * *(13.02)$ vs. 40.05 (11.60), $\mathrm{P}<0.01)$ body mass index $\left(23.18^{*}(2.18)\right.$ vs. $\left.23.65(2.46), \mathrm{P}<0.05\right)$ and body weight $(60.12 * *(6.24)$ vs. $53.10(6.95), \mathrm{P}<0.05)$ were significantly higher among men compared to women victims.

There was a high prevalence of sedentary behavior, alcohol and tobacco intake and obesity, among men compared to women (Table 1). Social classes 3-5 were comparable in the two sexes. The prevalence of underweight victims was $14.2 \%(n=315)$, overweight $29.4 \%(n=654)$ and obese $20.8 \%(n=461)$ as reported earlier [26].

Table 1. Prevalence of Risk Factors Among Patients Dying Due to Various Causes

\begin{tabular}{|l|l|l|}
\hline Risk Factors, $\mathbf{n}(\mathbf{\%})$ & Male $(\mathbf{n}=\mathbf{1 3 8 5})$ & Female $(\mathbf{n}=\mathbf{8 3 7})$ \\
\hline \hline Obesity (BMI $>25 \mathrm{~kg} / \mathrm{m} 2)$ & $277(20.0)$ & $184(22.0)$ \\
\hline Overweight $(23-24.9 \mathrm{~kg} / \mathrm{m} 2)$ & $470(33.9)^{*}$ & $184(22.0)$ \\
\hline Hypertension $(>140 / 90 \mathrm{mmHg})$ & $457(33.0)$ & $251(30.0)$ \\
\hline Diabetes mellitus (known) & $110(8.0)$ & $58(7.0)$ \\
\hline Social class 3-5 & $774(55.9)$ & $453(54.1)$ \\
\hline Sedentary behavior & $747(53.9)^{*}$ & $368(44.0)$ \\
\hline Tobacco intake & $623(45.0)^{* *}$ & $125(15.0)$ \\
\hline Salt intake $(>10 \mathrm{~g} /$ day) & $782(56.4)$ & $491(58.6)$ \\
\hline Alcoholism $(>20$ drinks/week) & $65(4.7)^{* *}$ & $1(0.12)$ \\
\hline
\end{tabular}

$*=\mathrm{P}<0.05, * *=\mathrm{P}<0.001, \mathrm{P}$ value were obtained by chi square test by comparison of frequencies in the two groups. 
As given in Fig. (1), using the modified verbal autopsy questionnaire allowed us to diagnose $57.0 \%$ deaths due to NCDs, $25.5 \%$ due to communicable diseases and $17.6 \%$ due to injury and accidents among both sexes. Among NCDs, $21.2 \%(n=471)$ deaths occurred due to CVDs (CAD, sudden cardiac deaths, heart failure), $7.9 \%(\mathrm{n}=175)$ due to stroke and $2.2 \%(\mathrm{n}=49)$ due to diabetic vascular disease (Fig. 2). Thus majority of the deaths were due to vascular diseases $(31.3 \%$, $\mathrm{n}=695$ ) (Fig. 3). Renal diseases including acute renal failure and chronic renal failure were the cause of death among $11.2 \%(\mathrm{n}=250)$ of victims, cancers $5.9 \%(\mathrm{n}=131)$, chronic lung disease $8.6 \%(\mathrm{n}=192)$ and cirrhosis liver $1.2 \%(\mathrm{n}=27)$ of the victims (Figs. 2,3). Using the modified questionnaires most of the victims could be classified relatively more accurately, into various causes of death according to body systems (Figs. 1,2 and 3).

Table 2 shows the food intakes in men and women. The consumption of prudent foods; cereals, fruits, vegetables, legumes and nuts as well as milk and curd were moderate in both the groups. Refined Western type foods; sugar, cola drinks, bread, biscuits, chocolates, cakes, refined cereals; corn flakes; clarified butter, butter, trans fat and w- 6 rich oils, meat and eggs and salt were also common food items consumed by both sexes. Table 2 also shows the food intakes among victims who died due to various NCDs; malignant, circulatory, chronic lung diseases, renal diseases and diabetes and communicable diseases, compared to those who died due to injury and accidents. We found an overall decrease in the consumption of prudent foods and an increase in the Western type foods with high w-6/w-3 ratio of fatty acids, among victims who died due to circulatory, malignant, chronic lung diseases, renal diseases and diabetes and infective causes of death compared to injury and accidents among both men and women. The diet score also showed a significant decreasing trend in both sexes as shown in Table 2. The trend for food intakes and dietary score were significant as revealed by the Kendall's $\tau$ (tau) test. Multivariate logistic regression analysis revealed that after adjustment for age, and body mass index, prudent foods and fruit, vegetable, legume and nuts intake were significantly inversely associated with deaths due to various diseases whereas Western type foods, meat and eggs and refined foods intake as well as high $\mathrm{w}-6 / \mathrm{w}-3$ ratio of fatty acids were positively associated with causes of deaths due to non-communicable diseases (Table $\mathbf{3}$ ).

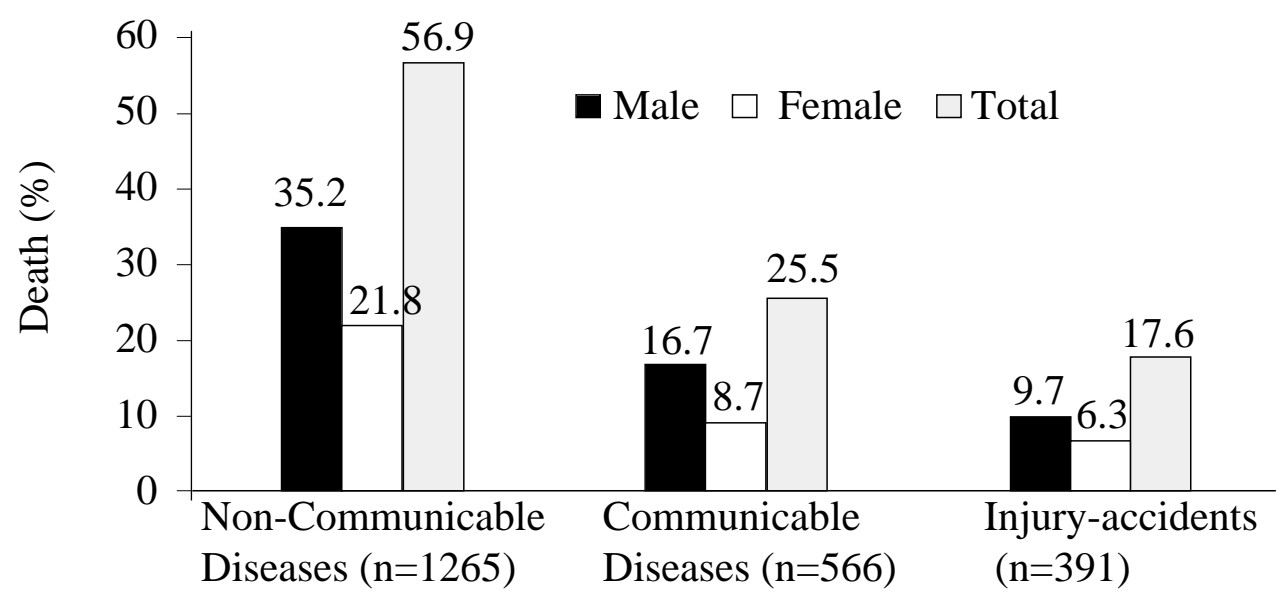

Fig. (1). Prevalence of broad causes of deaths in north India.

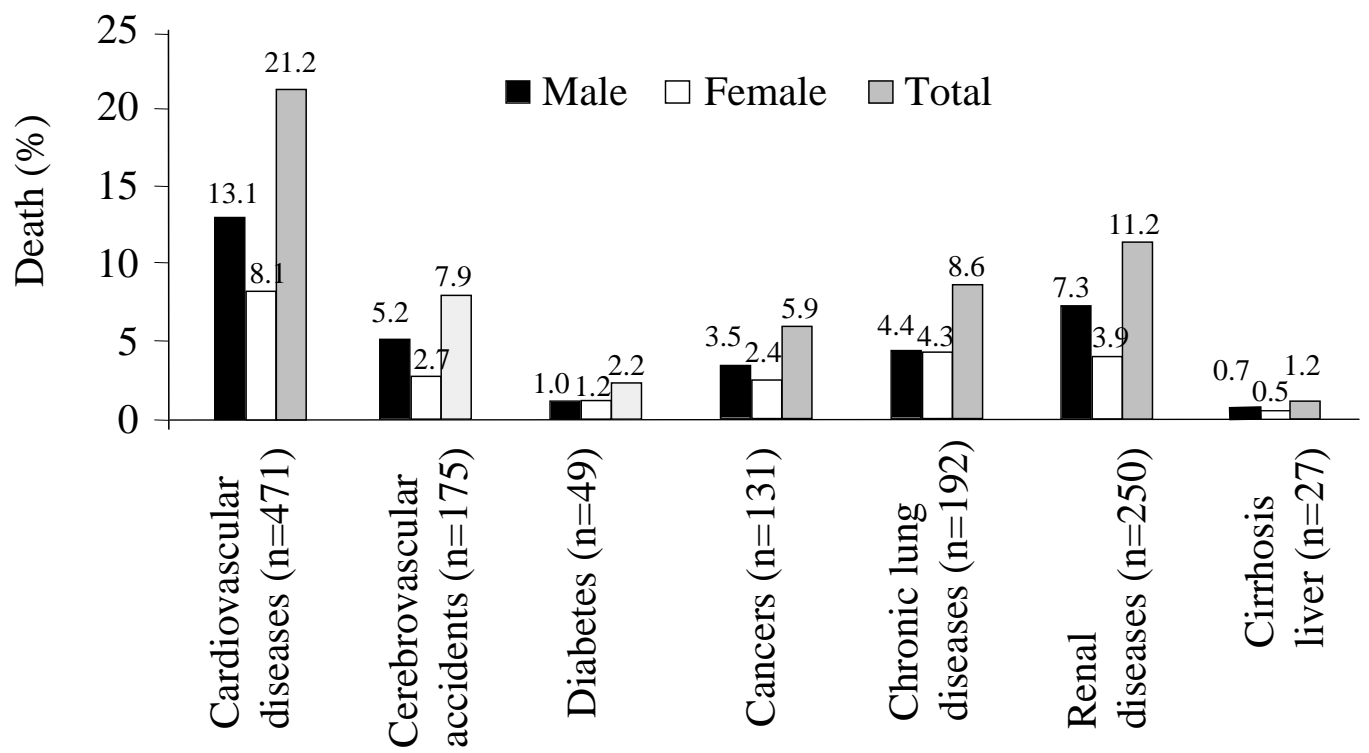

Fig. (2). Prevalence of causes of deaths in age 25-64 years, due to non-communicable diseases in north India. 


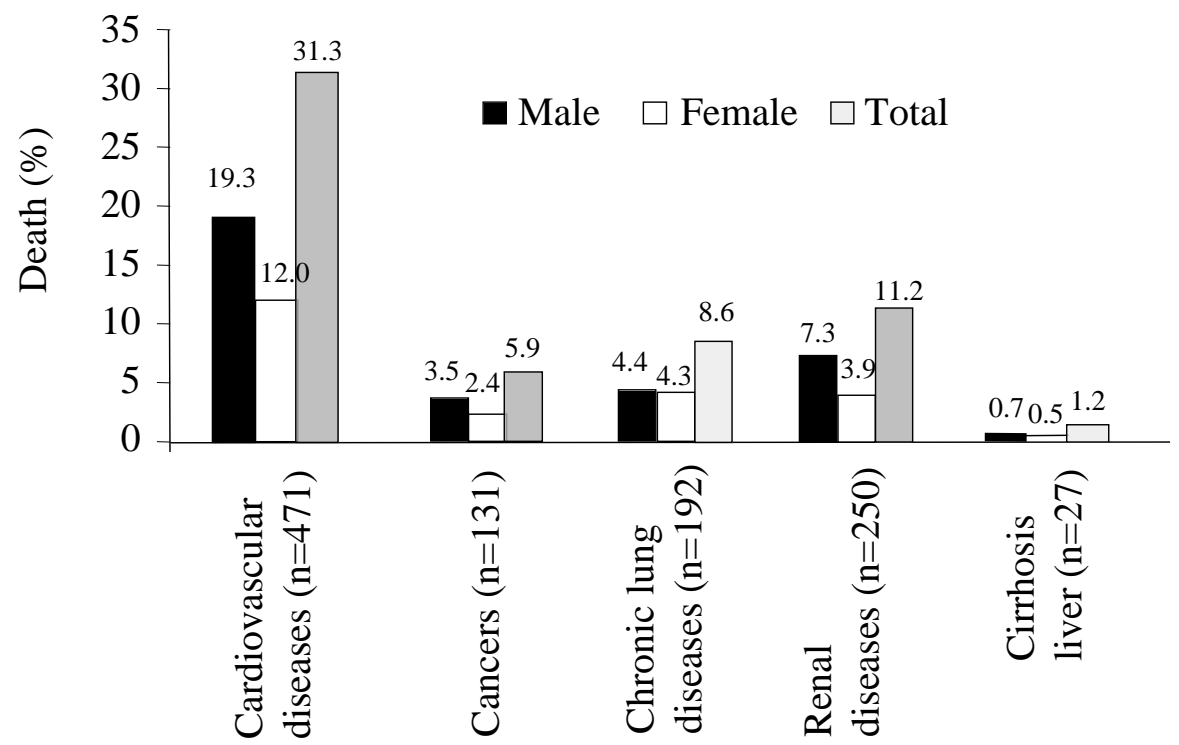

Fig. (3). Prevalence of causes of death due to cardiovascular diseases and other chronic diseases in north India.

Table 2. Food Intakes and w-6/w-3 Fatty Acid Ratio of Diet in Relation to Causes of Death Based on Assessment by Dietary Diaries of the Spouse and Questionnaires Filled by the Nutritionist

\begin{tabular}{|c|c|c|c|c|c|}
\hline Causes of Death & Prudent Diet & Western Type Diet & Total Foods & Score & w-6/w-3 Ratio \\
\hline $\mathrm{n}=1385$ & \multicolumn{5}{|c|}{$\operatorname{Men}($ Mean \pm Standard deviation $) g /$ day } \\
\hline Injury-accidents ( $\mathrm{n}=215$ ) & $892 \pm 252$ & $202 \pm 22$ & $1094 \pm 302$ & $7.93 \pm 2.8$ & $31.3 \pm 5.3$ \\
\hline Communicable Diseases. $(\mathrm{n}=372)$ & $806 \pm 237$ & $256 \pm 28$ & $1062 \pm 198$ & $7.26 \pm 2.7$ & $38.2 \pm 6.6$ \\
\hline \multicolumn{6}{|l|}{ NCDs } \\
\hline Malignant $(\mathrm{n}=77)$ & $715 \pm 241$ & $412 \pm 53$ & $1127 \pm 311$ & $6.44 \pm 2.5$ & $42.2 \pm 6.8$ \\
\hline Circulatory $(n=406)$ & $757 \pm 245$ & $437 \pm 47$ & $1194 \pm 318$ & $6.81 \pm 2.6$ & $45.3 \pm 8.3$ \\
\hline Chronic lung diseases(97) & $705 \pm 202$ & $405 \pm 41$ & $1110 \pm 302$ & $6.25 \pm 2.2$ & $42.0 \pm 7.4$ \\
\hline Kidney diseases $(\mathrm{n}=163$ & $617 \pm 188$ & $505 \pm 55$ & $1122 \pm 325$ & $5.72 \pm 1.8$ & $41.8 \pm 6.1$ \\
\hline Diabetes $(n=23)$ & $605 \pm 175$ & $522 \pm 61$ & $1127 \pm 334$ & $5.65 \pm 1.7$ & $41.6 \pm 5.7$ \\
\hline Kendall's $\Gamma$ & $0.045^{*}$ & $0.048^{* *}$ & 0.025 & $0.041^{*}$ & $0.042 *$ \\
\hline$. n=837$ & \multicolumn{5}{|c|}{ Women(Mean \pm Standard deviation)g/day } \\
\hline Injury-accidents ( $\mathrm{n}=139$ ) & $822 \pm 234$ & $186 \pm 23$ & $1008 \pm 224$ & $8.40 \pm 2.2$ & $25.5 \pm 5.7$ \\
\hline Communicable diseases $(\mathrm{n}=194)$ & $736 \pm 237$ & $218 \pm 33$ & $954 \pm 201$ & $7.51 \pm 1.9$ & $34.5 \pm 5.6$ \\
\hline \multicolumn{6}{|l|}{$\operatorname{NCDs}(n=502)$} \\
\hline Malignant $(\mathrm{n}=54)$ & $657 \pm 197$ & $305 \pm 35$ & $962 \pm 221$ & $6.70 \pm 1.8$ & $41.6 \pm 6.8$ \\
\hline Circulatory $(n=240)$ & $655 \pm 205$ & $332 \pm 41$ & $987 \pm 218$ & $6.68 \pm 1.7$ & $44.5 \pm 7.5$ \\
\hline Chronic lung diseases $(n=95)$ & $660 \pm 180$ & $382 \pm 48$ & $1029 \pm 180$ & $6.12 \pm 1.3$ & $40.0 \pm 6.5$ \\
\hline Renal diseases. $(\mathrm{n}=87)$ & $565 \pm 155$ & $380 \pm 130$ & $995 \pm 165$ & $5.57 \pm 1.1$ & $39.7 \pm 6.8$ \\
\hline Diabetes $(n=26)$ & $553 \pm 146$ & $387 \pm 135$ & $940 \pm 153$ & $5.53 \pm 1.1$ & $40.0 \pm 6.5$ \\
\hline Kendall's $\Gamma$ & $0.041^{*}$ & $0.067 * *$ & 0.024 & $0.043^{*}$ & $0.041^{*}$ \\
\hline
\end{tabular}

Values are number mean (Standard deviation), ${ }^{*}=\mathrm{P}<0.01,{ }^{* *}=\mathrm{P}<0.001$.

\section{DISCUSSION}

This study showes that NCDs such as malignant, circulatory, chronic lung disease, renal disease and diabetes mellitus were common causes $(57.0 \%)$ of death among both sexes (Figs. 1-3; Table 2). Infectious or communicable diseases were also the major causes of death among 
Table 3. Multivariate Logistic Regression Analysis for Association of Food and Nutrient Intakes with Risk of Death from Non-communicable Diseases, after Adjustment of Age and Body Mass Index Among Men and Women

\begin{tabular}{|c|c|}
\hline Risk Factor Men & Women \\
\hline Odds ratio, $(95 \%$ confidence interval $)$ & $\begin{array}{l}\text { Odds ratio, }(95 \% \text { confidence } \\
\text { interval) }\end{array}$ \\
\hline Prudent foods $1.11(1.06-1.18)^{* *}$ & $1.09(1.04-1.16)^{* *}$ \\
\hline FVL and nuts $1.07(1.02-1.12)^{* *}$ & $1.05(0.99-1.11)^{* *}$ \\
\hline Western type foods $1.02(0.95-1.09)^{*}$ & $1.00(0.94-1.06)^{*}$ \\
\hline Meat and eggs $1.00(0.94-1.06)^{*}$ & $0.98(0.93-1.04)^{*}$ \\
\hline Refined foods $0.98(0.91-1.05)^{*}$ & $0.95(0.89-1.02)^{*}$ \\
\hline $\mathrm{w}-6 / \mathrm{w}-3$ fat ratio $1.12(1.01-1.19)^{* *}$ & $1.11(1.00-1.18)^{* *}$ \\
\hline
\end{tabular}

*P value $<0.01, * *<0.001$. $\mathrm{OR}=$ Odds ratio. $\mathrm{FVL}=$ fruit, vegetable, legume.

Table 4. Omega-6: Omega-3 Ratios of Dietary Fatty Acids in Various Populations

\begin{tabular}{|l|l|l|}
\hline Population & $\mathbf{\omega 6 / \omega 3}$ & Ref. \\
\hline \hline Paleolithic & 0.79 & {$[2]$} \\
\hline Greece prior to 1960 & $1.00-2.00$ & {$[16]$} \\
\hline Current Japan & 4.00 & {$[16]$} \\
\hline Current India, rural & $5-6.1$ & {$[6]$} \\
\hline Current United Kingdom and northern Europe & 15.00 & {$[16]$} \\
\hline Current United States & 16.74 & {$[15]$} \\
\hline Current India, Urban & $38-50$ & {$[15]$} \\
\hline
\end{tabular}

decedents dying due to various causes. This observation is in agreement of UN HLM as well as WHO and World Bank $[1,7]$. These victims were consuming a diet characterized with high w-6/w-3 ratio of fatty acids (>40:1) with lower amount of prudent foods and greater amount of proatherogenic western type foods compared to food intakes among victims dying due to injury and accidents (Table 2). The odds ratios for consumption of high w-6/w-3 ratio of fatty acids rich prudent foods, fruit, vegetable, legume and nuts intake, indicating inverse association as well as for intake of Western type foods, meat and eggs and refined foods, indicating positive association, were significant (Table 3). We can not compare our results with other studies because such verbal autopsy studies on dietary patterns and risk of death among victims are not available. However, large scales cohort studies such as Nurses' Health Study [22, 23] based on data collected by questionnaires also confirm our findings about the role of Western diet and prudent diet in the pathogenesis of deaths due to NCDs. There is additional evidence showing ethnic differences in fatty acid concentrations in thrombocyte phospholipids, the ratios of omega-6/omega-3 fatty acids, and percentage of all deaths from cardiovascular disease in Japan and Europe and Greenland Eskimos indicating greater deaths in association with higher $w-6 / w-3$ ratio of fatty acids $[6,15]$.

Randomized, controlled intervention trials also confirm the role of high $w-6 / w-3$ ratio Mediterranean style diet in the pathogenesis of CAD [29-36]. The effect of Paleolithic style diet was examined in patients $(n=204$ intervention group, $\mathrm{n}=202$ control group) with acute coronary syndromes, which showed significant decline in total cardiac events as well as in total mortality after 6 weeks and the benefit continued after one year [29,30]. Further follow up for 2 years in this study [30] is different from the published work, because its emphasis is on the Paleolithic dietary patterns and ALA content of the diet to be responsible for the significant greater survival in the intervention group compared to control group. Dietary patterns before entry to the study showed higher $w-6 / w-3$ ratio of 32.5 in the diets of both the groups. Intervention group A was advised a Paleolithic style diet with $w-6 / w-3$ fatty acid ratio of 4.3 compared to standard diet group with ratio of 20. After a follow up of 2 years, total mortality was significantly declined in the Paleolithic style diet group compared to control group[30]. The mortality was lowest among subjects with $w-6 / w-3$ ratio of less than 10 which showed graded increase with increase in the fatty acid ratio in both the groups. The Lyon Heart Study was a dietary intervention trial in which a modified diet of Crete (Mediterranean style diet) was compared with the prudent diet $[31,32]$. The experimental diet provided a $\mathrm{w}-$ 6 to w-3 ratio of fatty acids of $4 / 1$ in the diet. This ratio was achieved by substituting olive oil and canola (oil) margarine for corn oil. Since olive oil is low in w- 6 whereas corn oil is high, $8 \%$ and $61 \%$ respectively, the w-3 incorporation into cell membranes was increased in the low w-6 diet. In this study, the ratio of $4 / 1$ of w-6/w-3 led to a $70 \%$ decrease in total mortality at the end of two years [32]. It is possible that

Table 5. Ethnic Differences in Fatty Acid Levels in Thrombocytes Phospholipids and Percentage of All Deaths from Cardiovascular Disease

\begin{tabular}{|c|c|c|c|}
\hline & Europe \& USA \% & Japan\% & Greenland Eskimos\% \\
\hline Ratio of $\omega-6 / \omega-3$ & 50 & 12 & 1 \\
\hline Mortality from cardiovascular disease & 45 & 12 & 7 \\
\hline
\end{tabular}

Modified from Singh et al. 2011, their references [6,15]. 
olive oil increases the incorporation of omega- 3 fatty acids whereas the w-6 fatty acids from corn oil competes [33]. Similar findings were observed by Singh et al., in the Indian experiments of infarct survival [34,35]. The Diet and Reinfarction Trial (DART) by Burr et al., reported a decrease in sudden death in the group that received fish advice or took fish oil supplements relative to the group that did not [36]. The GISSI Prevenzione Trial participants were on a traditional Italian diet plus $850-882 \mathrm{mg}$ of omega-3 fatty acids at a ratio of 2/1 EPA to DHA [37]. The intervention group had a decrease in sudden cardiac death by $45 \%$. Although there are no dietary data on total intake for omega6 and omega- 3 fatty acids, the difference in sudden death is most likely due to the increase of EPA and DHA and a decrease of arachidonic acid in cell membrane phospholipids. Prostaglandins derived from arachidonic acid are proarrhythmic, whereas the corresponding prostaglandins from EPA may be protective [8].

Singh et al., 2002, tested an 'Indo-Mediterranean diet' in 1000 patients in India, with existing coronary disease or at high risk for coronary disease [38]. Half of the patients $(\mathrm{n}=499$ vs. 501) were administered a diet rich in fruits, vegetables, whole grains, walnuts, mustard and soy bean oil as a source for $\mathrm{w}-3$ fat and the rest viz. 501 patients were advised to take prudent diet advised by the National Cholesterol Education Program step 1 diet in 1988. At the end of 2 year follow up, the Paleolithic style diet group consumed significantly more fruits, vegetables and legumes

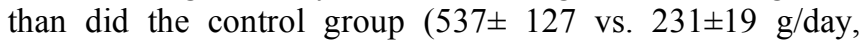
$\mathrm{p}<0.001)$ as well as more mustard and soy bean oil $(31 \pm 6.5$ vs. $15.2 \pm 5.5 \mathrm{~g} /$ day). The mean intake of ALA was over two fold greater in the Paleolithic style diet group compared to control group. (1.8 \pm 0.4 vs. $0.8 \pm 0.2 \mathrm{~g} / \mathrm{day}, \mathrm{p}<0.001)$. The w6/w-3 ratio of fatty acids calculated by Pella et al., was slightly higher at baseline in the intervention group than in the control group $(39 \pm 12$ vs. $34 \pm 10)$ yet both these values are extremely high, reflecting a diet with a very high w-6 content yet low w-3 [39]. At the end of two years follow up, this ratio showed a marked decline in the intervention group, which was greater than that observed in the control group consuming control diet $(9.1 \pm 12$ vs. $21 \pm 10, p<0.001)$. The study end points were; significant decline in the total cardiac events, sudden cardiac death and non-fatal infarction in the intervention group compared to the control group. Except for the Lyon Heart Study, most of the cardiovascular disease omega-3 fatty acids supplementation trials did not attempt to modify the consumption of other fat components, and specifically did not seek to reduce the intake of omega- 6 fatty acids despite the fact that there is convincing support for such studies. Yokoyama et al., investigated the effects of EPA on major coronary events in hypercholesterolemic patients in a randomized open label, blinded analysis [40]. Patients were randomly assigned to receive either $1800 \mathrm{mg}$ of EPA with statin or statin only in a 5-year follow up. The results showed that EPA is a promising treatment for prevention of major coronary events, and especially nonfatal coronary events, in Japanese hypercholesterolemic patients. This is a very important finding because the Japanese already have a high fish intake. These findings further support the data from the study by Iso et al., that showed, compared with a modest fish intake of once a week or about
$20 \mathrm{~g} / \mathrm{d}$, a higher intake was associated with substantially reduced risk of coronary heart disease, primarily nonfatal cardiac events, among middle-aged persons [41].

The role of balancing the $\mathrm{w}-6$ to $\mathrm{w}-3$ ratio of fatty acids was shown in a randomized, controlled, 3-diet, 3-period crossover study in which 22 hypercholesterolemic subjects were assigned to 3 experimental diets: a diet high in w-3 diet; (6.5\% of energy) a diet high in w- 6 (w- $6,12.6 \%$ of energy), and an average American diet for 6 weeks [42]. The results showed that on the w-3 diet, IL-6, IL $1 \beta$, and TNFproduction by peripheral blood mononuclear cells and serum TNF-alpha concentrations were lower $(\mathrm{P}<0.05$ and $\mathrm{P}<0.08$ respectively) than with the w-6 diet or American diet. The production of TNF-alpha by mononuclear cells was inversely correlated with w-3 $(\mathrm{P}=0.07)$ and with eicosapentaenoic acid $(\mathrm{P}=0.03)$ concentrations in mononuclear cells lipids with the w-3 diet. Changes in serum alpha linolenic acid(ALA) were inversely correlated with changes in TNFalpha produced by mononuclear cells $(\mathrm{P}<0.05)$. In this study the increased intake of dietary w-3 elicited antiinflammatory effects by inhibiting IL-6, IL-1 $\beta$, and TNFalpha production in cultured cells. Changes in mononuclear ALA and EPA derived from ALA are associated with beneficial changes in TNF-alpha release. The cardioprotective effects of ALA are mediated in part by a reduction in the production of inflammatory cytokines, IL-6, IL-1 $\beta$, and TNF-alpha. Since Paschos et al., reported a decline in blood pressures by ALA [43], these results are important because they strongly suggest that the w-3 (ALA) intake at a ratio of $1-2 / 1$ which is simple to implement, is beneficial. Further studies in which the ratio of $\mathrm{w}-6 / \mathrm{w}-3$ was not balanced, failed to decrease C-reactive protein or IL-6, IL$1 \beta$, or TNF-alpha leading to wrong conclusions that $\mathrm{w}-6$ is not inflammatory [44]. Raheja et al., reported a higher ratio of $w-6 / w-3$ fatty acid in the diet in India which was associated with type 2 diabetes [45]. In patients with rheumatoid arthritis, decrease in w- $6 / \mathrm{w}-3$ ratio was reported to cause beneficial effects [46]. In a further study by James and Cleland, the potential use of omega-3 fatty acids within a dietary framework of an omega-6/omega-3 ratio of 3-4/1 was studied, by supplying $4 \mathrm{~g}$ of EPA+DHA and using flaxseed oil rich in ALA [46]. In their studies, the addition of $4 \mathrm{gm}$ EPA and DHA in the diet produced a substantial inhibition of production of IL- $1 \beta$ and TNF-alpha when mononuclear cell levels of EPA were equal or greater than $1.5 \%$ of total cell phospholipid fatty acids which correlated with a plasma phospholipid EPA level equal to or greater than $3.2 \%$. The potential for complementarity between drug therapy and dietary choices appears to be clear from this study, that increased intake of omega-3 fatty acids and decreased intake of omega- 6 fatty acids may lead to drugsparing effects. It is possible that fat composition of the background diet, and the issue of concurrent drug use should be evaluated in further studies. A diet rich in omega-3 fatty acids and poor in omega- 6 fatty acids provides the appropriate background biochemical environment in which drugs function and show their activity and ability.

Apart from cardiovascular diseases and diabetes mellitus which caused $31.3 \%,(n=695)$ of deaths in our study, chronic lung disease including asthma were the cause of death among $8.6 \%(\mathrm{n}=192)$ victims (Figs. 1-3). These victims were 
consuming a high $\mathrm{w}-6 / \mathrm{w}-3$ ratio of $41: 1$ diet. Asthma is a mediator driven inflammatory process in the lungs and the leukotrienes and prostaglandins are implicated in the inflammatory cascade that occurs in asthmatic airways [47, 48]. Mast cells, macrophages, eosinophils, and lymphocytes are common cells involved in asthma. The leukotrienes are potent inducers of bronchospasm, airway edema, mucus secretion, and inflammatory cell migration, all of which are important to the asthmatic symptomatology. The inflammatory mediators include cytokines and growth factors (peptide mediators) as well as the eicosanoids, which are the products of arachidonic acid metabolism, which are important mediators in the underlying inflammatory mechanisms of asthma (Fig. 3). Broughton et al., [47] studied the effect of omega-3 fatty acids at a ratio of omega-6/omega- 3 of $10 / 1$ to $5 / 1$ in an asthmatic population in ameliorating methacholine-induced respiratory distress. Methacholine-induced respiratory distress increased in presence of low w-3 fatty acids. However, increase in omega-3 fatty acid ingestion, was associated with increase in urinary 5-series leukotriene excretion, predicted treatment efficacy and a dose change in $40 \%$ of the test subjects (responders) whereas the non-responders had a further loss in respiratory capacity. A urinary ratio of 4-series to 5-series of $<1$ induced by omega-3 fatty acid ingestion may predict respiratory benefit. There is evidence of airway inflammation even in newly diagnosed asthma patients within 2-12 months after their first symptoms [48].

Our study shows that $5.9 \%(n=131)$ deaths were due to cancers (Figs. $2 \& 3$ ) and these victims were consuming high w-6/w-3 ratio of 42:1 diet. In a case-control study by Shannon et al., in China on the relationship between fatty acids and breast cancer, the results supported a positive effect of omega-3 fatty acids on breast cancer risk and provide additional evidence for the importance of evaluating the ratio of fatty acids when evaluating diet and breast cancer risk [18]. Bartram et al., [49] administered fish oil in order to suppress rectal epithelial cell proliferation and prostaglandin $\mathrm{E}_{2}\left(\mathrm{PGE}_{2}\right)$ biosynthesis. This was achieved when the dietary omega-6/omega-3 ratio was $2.5 / 1$ but not with the same absolute level of fish oil intake and an omega-6/omega-3 ratio of 4/1. Recently, Maillard et al., reported their results on a case control study [50]. They determined omega-3 and omega- 6 fatty acids in breast adipose tissue and relative risk of breast cancer. Fatty acid levels in breast adipose tissue reflect dietary intake of fatty acids and suggested a protective effect of omega-3 fatty acids on breast cancer risk and support the hypothesis that the balance between omega- 3 and omega- 6 fatty acids plays a role in breast cancer.

Osteoporosis represents a major challenge in bone and joint diseases, particularly with increases in the elderly population worldwide. Bone mineral accrual during childhood and adolescence plays a vital role in preventing deaths and disability due to osteoporosis in the later life. The identification of factors influencing peak bone mass are important for the prevention of osteoporosis and related fractures. Genetic factors are responsible for about $70 \%$ of the variance in bone mass [51] and the rest viz. 30\% may be due to nutrition, physical activity, and body mass index [52]. Experimental studies have shown that dietary intake of longchain w-3 fatty acids may influence both bone formation and bone resorption and an increase in periosteal bone formation [53]. Kartikey et al., observed a higher dietary w-6/w-3 fatty acid ratio of the diet and higher levels of proinflammatory cytokines IL-6 and TNF-alpha with risk of osteoporosis and hip joint fracture [54].

The Rancho Bernardo Study by Weiss et al., [55] was carried out in 1532 community-dwelling men and women aged 45-90 years, between 1988 and 1992 on the association of dietary w-6/w-3 fatty acid ratio and bone mineral density. The average intake of total w-3 fatty acids was $1.3 \mathrm{~g} / \mathrm{d}$ and the average ratio of total $\mathrm{w}-6 / \mathrm{w}-3$ fatty acids was 8.4 in men and 7.9 in women. There was a significant inverse association between the ratio of dietary LA (w-6) to ALA (w-3) and bone mineral density (BMD) at the hip in 642 men, 564 women not using hormone therapy, and 326 women using hormone therapy. Age, body mass index, and lifestyle factors and increasing ratio of total dietary w-6/w-3 fatty acids was also significant and independently associated with lower BMD at the hip in all women and at the spine in women not using hormone therapy. It is possible that the relative amounts of dietary omega- 6 and omega- 3 fatty acids may play a vital role in preserving skeletal integrity of old age. In a cohort study by Hogstrom et al., [56], the aim of the 8 -year study was to investigate a possible role of fatty acids in bone accumulation and the attainment of peak bone mass in young post-pubertal males. This study is the first to examine the association between individual PUFAs, BMD, and bone mineral accrual. BMD of the total body measured at 22 years of age showed a significant negative correlation with serum oleic acid and mono-unsaturated fatty acids and a significant positive correlation with DHA and omega-3 fatty acids. BMD of the spine showed a positive association with DHA and omega- 3 fatty acids. Changes in BMD of the spine between 16 and 22 years of age showed a positive association with DHA and w-3 fatty acids, and a negative association with the $\mathrm{w}-6 / \mathrm{w}-3$ ratio [56]. The study adds to the growing body of evidence that omega- 3 fatty acids are beneficial to bone health. Animal models have suggested that omega-3 fatty acids may attenuate postmenopausal bone loss.

Inflammation of the lacrimal gland, the meibomian gland, and the ocular surface plays a significant role in dry eye syndrome (DES) [57]. Increased concentrations of inflammatory cytokines, such as IL-1, IL-6, and TNF-alpha have been found in tear film in patients with DES [57]. In the Women's Health Study [58] by Miljanovic et al., a higher ratio of w-6/w-3 consumption was associated with a significantly increased risk of DES (OR: 2.51; 95\% CI: 1.13 , 5.58 ) for $15: 1$ versus $<4.1$ ( $\mathrm{P}$ for trend $=0.01$ ). A higher dietary intake of $\mathrm{w}-3$ fatty acids is associated with a decreased incidence of DES in women and a high w-6/w-3 ratio is associated with a greater risk. After 65 years of age, age-related macular degeneration (AMD) is the leading cause of vision loss. Both AMD and cardiovascular disease share similar modifiable factors [59]. Fish intake has been reported to have protective properties in lowering the risk of AMD, especially when LA intake was low [60]. In a study involving twins, Seddon et al., showed that fish consumption and omega-3 fatty acid intake reduce the risk of AMD whereas cigarette smoking increases the risk for AMD [61]. 
Psychological stress appears to be associated with an imbalance of w-6 and w-3 PUFA in the peripheral blood causing, an overproduction of proinflammatory cytokines interferon gamma and TNF-alpha, IL-6 and IL-1. There is evidence that changes in fatty acid composition are involved in the pathophysiology of major depression and suicides among patients with depression [62]. Changes in serotonin (5-HT) receptor number and function caused by changes in PUFA provide the theoretical rationale connecting fatty acids with the current receptor and neurotransmitter theories of depression [63-65].

The increased $\mathrm{C} 20: 46 / \mathrm{C} 20: 53$ ratios and the imbalance in the $\mathrm{w}-6 / \mathrm{w}-3$ PUFA ratio in major depression may be related to the increased production of proinflammatory cytokines and eicosanoids in that illness [64]. There are a number of studies evaluating the therapeutic effect of EPA and DHA in major depression. Kiecolt-Glaser et al., studied depressive symptoms, w- $6 / \mathrm{w}-3$ fatty acid ratio and inflammation in older adults [66]. As the dietary ratio of w-6/w-3 increased, the depressive symptoms, TNF-alpha, IL-6, and IL-6 soluble receptor (sIL-6r) increased.

Fig. (4) shows the association of high $w-6 / w-3$ ratio of the diets with various causes of death in our study indicating higher death rates due to NCDs with increase in ratio compared to lowest ratio among decedents dying due to injury and accidents. The causes of deaths due to injury and accidents also included deaths due to suicides and depression and, osteoporotic hip joint fractures which need further analysis to emphasize the role of high $\mathrm{w}-6 / \mathrm{w}-3$ ratio diet in the pathogenesis of these NCDs.

In brief, it is possible that w-3 fatty acids play an important role in health and disease and favorably affect cardiovascular function, beta cell function, skeletal and neuronal growth. The attainment of peak bone mass in adolescence and the prevention of age-related macular degeneration are potential positive effects of omega- 3 fatty acids [67-74]. High w-6/w-3 fatty acid ratio appears to be important in the pathogenesis of other NCDs. The findings in our study indicate that low w-6/w-3 fatty acid ratio, IndoMediterranean dietary patterns may be inversely associated and a Western type foods intake, are significant predictors of

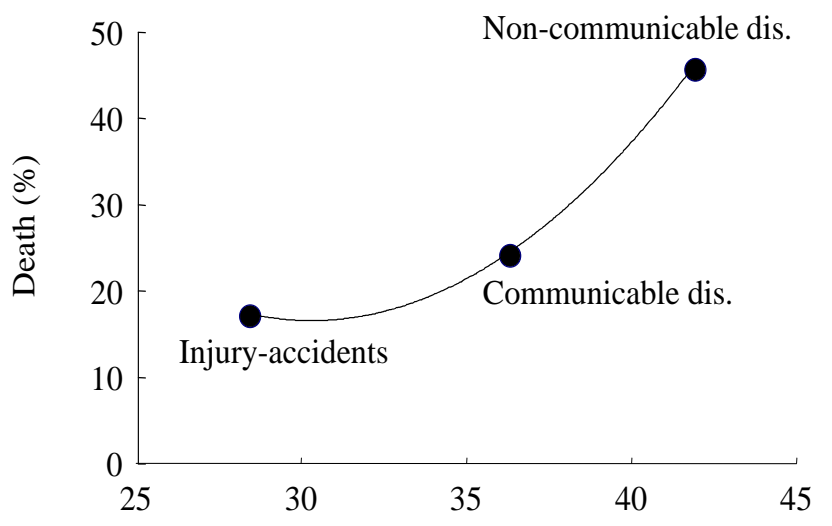

\section{W-6/W-3 ratio}

Fig. (4). Association of w-6/w-3ratio of fatty acids with mortality due to injury- accidents, communicable diseases and non-communicable diseases. deaths due to circulatory diseases and other chronic diseases. Larger studies are necessary to confirm our findings.

\section{RESPONSIBILITIES}

Study design, questionnaire, writing of manuscript by RBS, collection of data by VS, SKK, RBS. Others experts; VM, DP, SS helped in the analysis of data and other authors in the writing of manuscript, calculations, review of references and editing.

\section{ACKNOWLEDGEMENTS}

We are grateful to Centre of Nutrition Research, International College of Nutrition for the financial support for conducting this study.

\section{CONFLICT OF INTEREST}

Declared none.

\section{REFERENCES}

[1] Beaglehole R, Bonita R, Alleyne G, et al. UN High-Level Meeting on Non-Communicable Diseases: addressing four questions. Lancet 2011; 378: 449-55

[2] Eaton SB, Eaton SB III, Sinclair AJ, Cordain L, Mann NJ. Dietary intake of long-chain polyunsaturated fatty acids during the Paleolithic. World Rev Nutr Diet 1998; 83: 12-23.

[3] Bantle JP. Dietary fructose and metabolic syndrome and diabetes. J Nutr 2009; 139: 1263S-8S.

[4] Johnson RK, Appel LJ, Brands M, et al. Dietary sugars intake and cardiovascular health. A scientific statement from the American Heart Association, on behalf of the American Heart Association Nutrition Committee of the Council on Nutrition, Physical Activity, and Metabolism and the Council on Epidemiology and Prevention. Circulation 2009; 120: 1011-20.

[5] Lim JS, Mietus-Snyder M, Valente A, Schwarz JM, Lustig RH. The role of fructose in the pathogenesis of NAFLD and the metabolic syndrome. Nat Rev Gastroenterol Hepatol 2010; 7: 251-64.

[6] Singh RB, De Meester F, Wilczynska A. The tsim tsoum approaches for prevention of cardiovascular disease. Cardiol Res Pract 2010; 2010: 18.

[7] WHO. Mortality and burden of disease estimates for WHO Member States in 2008. Geneva: World Health Organization 2010.

[8] Simopoulos AP. Evolutionary aspects of diet, the omega-6/omega3 ratio and genetic variation: nutritional implications for chronic diseases. Biomed Pharmacol 2006; 60: 502-7.

[9] Weber PC. Are we what we eat? Fatty acids in nutrition and in cell membranes: cell functions and disorders induced by dietary conditions. Report no. 4, Svanoybukt, Norway: Svanoy Foundation pp. 9-18, 1989.

[10] Endres S, Ghorbani R, Kelley VE. The effect of dietary supplementation with $\mathrm{n}-3$ polyunsaturated fatty acids on the synthesis of interleukin-1 and tumor necrosis factor by mononuclear cells. N Engl J Med 1989; 320: 265-8.

[11] Crawford MA. Fatty acid ratios in free-living and domestic animals. Lancet 1968; 291: 1329-33.

[12] Cordain L, Martin C, Florant G, Watkins BA. The fatty acid composition of muscle, brain, marrow and adipose tissue in elk: evolutionary implications for human dietary requirements. World Rev Nutr Diet 1998; 83: 225.

[13] Sinclair AJ, Slattery WJ, O'Dea K. The analysis of polyunsaturated fatty acids in meat by capillary gas-liquid chromatography. J Food Sci Agric 1982; 33: 771-6.

[14] Singh RB, DeMeester F, Mechirova V, Pella D, Otsuka K. Fatty acids in the causation and therapy of metabolic syndrome. In: DeMeester F, Watson RR, Eds. Wild type foods in health promotion and disease prevention. NJ: Humana Press 2008; pp. 263-84.

[15] Singh RB, Moshiri M, De Meester F, Juneja L, Muthusamy V, Manoharan $\mathrm{S}$. The evolution of low $\mathrm{w}-6 / \mathrm{w}-3$ ratio dietary pattern and risk of cardiovascular diseases and diabetes. J Altern Med Res 2011; 3: 45-70. 
[16] Simopoulos AP. The importance of the omega-6/omega-3 fatty acid ratio in cardiovascular disease and other chronic diseases. Exp Biol Med 2008; 233: 674-88.

[17] Esposito K, Giugiliano D. Diet and inflammation: a link to metabolic and cardiovascular diseases. Eur Heart J 2006; 27: 15-20.

[18] Shannon J, King IB, Moshofskky R, et al. Erythrocyte fatty acids and breast cancer risk: a case-control study in Shanghai, China. Am J Clin Nutr 2007; 85: 1090-7.

[19] Iqbal R, Anand S, Ounpuu S, et al. Dietary patterns and the risk of acute myocardial infarction in 52 countries: results of the INTERHEART study. Circulation 2008; 118: 1929-37.

[20] He FJ, Nowson CA, Lucas M, MacGregor GA. Increased consumption of fruit and vegetables is related to a reduced risk of coronary heart disease: meta-analysis of cohort studies. J Hum Hypertens 2007; 21: 717-28.

[21] Katcher HI, Legro RS, Kunselman AR, et al. The effects of whole grain- enriched hypocaloric diet on cardiovascular disease risk factors in men and women with metabolic syndrome. Am J Clin Nutr 2008; 87: 79-90.

[22] Fung TT, Malik V, Rexroad KM, Manson JE, Willett WC, Hu FB. Sweetened beverage consumption and risk of coronary heart in women. Am J Clin Nutr 2009; 89: 1037-42.

[23] Heidemann C, Schulze MB, Franco OH, van Dam RM, Mantzoros CS, Hu FB. Dietary patterns and risk of mortality from cardiovascular disease, cancer, and all causes in a prospective cohort of women. Circulation 2008; 118: 230-7.

[24] Singh RB, De Meester F, Pella D, Basu TK, Watson R. Globalization of dietary wild foods protect against cardiovascular disease and all cause mortalities? A Scientific statement from the International College of Cardiology, Columbus Paradigm Institute and the International College of Nutrition. Open Nutr J 2009; 2: 42-5.

[25] Singh RB, Fedacko J, Vargova V, et al. Singh's verbal autopsy questionnaire for assessment of causes of death, social autopsy, tobacco autopsy, and dietary autopsy based on medical records and interview. Acta Cardiol 2011; 66: 471-81.

[26] Singh RB, Singh S, Singh V, Kulshresth SK, Mechirova V, Pella D. Association of increased mortality with underweight, overweight and obesity among urban descents in north India dying due to various causes. World Heart J 2008; 1: 341-7.

[27] Singh RB, Singh V, Kulshrestha SK, et al. Social class and all cause mortality in an urban population of north India. Acta Cardiol 2005; 60: 611-7.

[28] Narsingrao BS, Deasthale YG, Pant KC. Nutrient composition of indian foods. New Delhi: Indian Council of Medical Research 1989.

[29] Singh RB, Rastogi SS, Verma R, Bolaki L, Singh R. An Indian experiment with nutritional modulation in acute myocardial infarction. Am J Cardiol 1992; 69: 879-85.

[30] Singh RB, Fedacko J, Vargova V, Niaz MA, Rastogi SS, Ghosh S. Effect of low W-6/W-3 ratio fatty acid Paleolithic style diet in patients with acute coronary syndromes. A randomized, single blind, controlled trial. World Heart J 2012; 4. (in press)

[31] de Lorgeril M, Renaud S, Mamelle N, et al. Mediterranean alphalinolenic acid-rich diet in secondary prevention of coronary heart disease. Lancet 1994; 343: 1454-9.

[32] de Logeril M, Salen P, Martin JL, Monjaud I, Delaye J, Mamelle $\mathrm{N}$. Mediterranean diet, traditional risk factors and the rate of cardiovascular complications after myocardial infarction. Final report of the Lyon Diet Heart Study. Circulation 1999; 99: 779-85.

[33] Cleland LG, James MJ, Neumann MA, D'Angelo M, Gibson RA. Linoleate inhibits EPA incorporation from dietary fish-oil supplements in human subjects. Am J Clin Nutr 1992; 55: 395-9.

[34] Singh RB, Rastogi SS, Verma R, et al. Randomized controlled trial of cardioprotective diet in patients with recent acute myocardial infarction: results of one year follow up. BMJ 1992; 304: 1015-9.

[35] Singh RB, Niaz MA, Sharma JP, Kumar R, Rastogi V, Moshiri M. Randomized, double-blind, placebo-controlled trial of fish oil and mustard oil in patients with suspected acute myocardial infarction: the Indian experiment of infarct survival - 4. Cardiovase Drugs Ther 1997; 11: 485-91.

[36] Burr ML, Fehily AM, Gilbert JF, et al. Effect of changes in fat, fish and fibre intakes on death and myocardial reinfarction: diet and reinfarction trial (DART). Lancet 1989; 2: 757-61.

[37] GISSI-Prevenzione Investigators. Dietary supplementation with n-3 polyunsaturated fatty acids and vitamin $\mathrm{E}$ after myocardial infarction: results of the GISSI-Prevenzione trial. Lancet 1999; 354: 447-55.

[38] Singh RB, Dubnov G, Niaz MA, et al. Effect of an IndoMediterranean diet on progression of coronary disease in high risk patients: a randomized single blind trial. Lancet 2002; 360: 1455-61.

[39] Pella D, Dubnov G, Singh RB, Sharma R. Effects of an IndoMediterranean diet on the omega-6/omega-3 ratio in patients at high risk of coronary artery disease: the Indian paradox. World Rev Nutr Diet 2003; 92: 74-80

[40] Yokoyama M, Origasa $\mathrm{H}$, Matsuzaki $\mathrm{M}$, et al. Effects of eicosapentaenoic acid on major coronary events in hypercholesterolaemic patients (JELIS): a randomised open-label, blinded endpoint analysis. Lancet 2997; 369: 1090-8.

[41] Iso H, Kobayashi M, Ishihara J, et al. Intake of fish and n3 fatty acids and risk of coronary heart disease among Japanese. The Japan Public Health Center-Based (JPHC) Study Cohort I. Circulation 2006; 113: 195-202.

[42] Zhao G, Etherton TD, Martin KR, Gillies PJ, West SG, KrisEtherton PM. Dietary alpha-linolenic acid inhibits proinflammatory cytokine production by peripheral blood mononuclear cells in hypercholesterolemic subjects. Am J Clin Nutr 2007; 85: 385-91.

[43] Paschos GK, Magkos F, Panagiotakos DB, Votteas V, Zampelas A. Dietary supplementation with flaxseed oil lowers blood pressure in dyslipidaemic patients. Eur J Clin Nutr 2007; 61(10): 1201-6.

[44] Toborek M, Lee YW, Garrido R, Kaiser S, Hennig B. Unsaturated fatty acids selectively induce an inflammatory environment in human endothelial cells. Am J Clin Nutr 2002; 75: 119-25.

[45] Raheja BS, Sadikot SM, Phatak RB, Rao MB. Significance of the $\mathrm{n}-6 / \mathrm{n}-3$ ratio for insulin action in diabetes. Ann NY Acad Sci 1993; 683: 258-71.

[46] James MJ, Cleland LG. Dietary n-3 fatty acids and therapy for rheumatoid arthritis. Semin Arthritis Rheum 1997; 27: 85-97.

[47] Broughton KS, Johnson CS, Pace BK, Liebman M, Kleppinger KM. Reduced asthma symptoms with n-3 fatty acid ingestion are related to 5-series leukotriene production. Am J Clin Nutr 1997; 65: 1011-7.

[48] Laitinen LA, Laitinen A, Haahtela T. Airway mucosal inflammation even in patients with newly diagnosed asthma. Am Rev Respir Dis 1993; 147: 697-704.

[49] Bartram HP, Bostner A, Scheppach W, et al. Effects of fish oil on rectal cell proliferation, mucosal fatty acids, and prostaglandin $\mathrm{E}_{2}$ release in healthy subjects. Gastroenterology 1993; 105: $1317-22$

[50] Maillard V, Bougnoux P, Ferrari P, et al. w-3 and n-6 fatty acids in breast adipose tissue and relative risk of breast cancer in a case-control study in Tours, France. Int J Cancer 2002; 98: 78-83.

[51] Eisman JA. Genetics of osteoporosis. Endocr Rev 1999; 20 788-894.

[52] Seeman H, Hopper JL, Bach LA, et al. Reduced bone mass in daughters of women with osteoporosis. N Engl J Med 1989; 320: 554-8.

[53] Cummings SR, Nevitt MC, Browner WS, et al. Risk factors for hip fracture in white women. Study of osteoporosis fracture research group. N Engl J Med 1995; 332: 767-73.

[54] Kartikey K, Singh G, Kidyore B, Somsunder YA, Howarth P. Association of dietary W-6/W-3 fatty acid ratio and inflammation with risk of hip joint fracture. Open Nutr J 2010; 3: 1-5.

[55] Weiss LA, Barret-Connor E, von Muhlen D. Ratio of n-6 to n-3 fatty acids and bone mineral density in older adults: the Rancho Bernardo Study. Am J Clin Nutr 2005; 81: 934-8.

[56] Hogstrom M, Nordstrom P, Nordstrom A. n-3 fatty acids are positively associated with peak bone mineral density and bone accrual in healthy men: the $\mathrm{NO}_{2}$ study. Am J Clin Nutr 2007; 85: 803-7.

[57] Miljanovic B, Trivedi KA, Dana MR, Gilbard JP, Buring JE, Schaumberg DA. Relation between dietary n-3 and n-6 fatty acids and clinically diagnosed dry eye syndrome in women. Am J Clin Nutr 2005; 82: 887-93.

[58] Snow KK, Seddon JM. Do age-related macular degeneration and cardiovascular disease share common antecedents? Ophthalmic Epidemiol 1999; 6: 125-43.

[59] Seddon JM, Chen CA. Epidemiology of age-related macular degeneration. $4^{\text {th }}$ ed. In: Ryan SJ, Ed. Retina: medical retina. vol. 2. St. Louis, MO: CV Mosby 2005. 
[60] Seddon JM, Cote J, Rosner B. Progression of age-related macular degeneration: association with dietary fat, transunsaturated fat, nuts, and fish intake. Arch Ophthalmol 2003; 121: 1728-37.

[61] Seddon JM, George S, Rosner B. Cigarette smoking, fish consumption, omega-3 fatty acid intake, and associations with agerelated macular degeneration. The US Twin Study of age-related macular degeneration. Arch Ophthalmol 2006; 124: 995-1001.

[62] Hibbeln JR, Salem N Jr. Dietary polyunsaturated fatty acids and depression: when cholesterol does not satisfy. Am J Clin Nutr 1995; 62: 1-9.

[63] Hibbeln JR, Umhau JC, Linnoila M, et al. A replication study of violent and nonviolent subjects: cerebrospinal fluid metabolites of serotonin and dopamine are predicted by plasma essential fatty acids. Biol Psychiatry 1998; 44: 243-9.

[64] Maes M, Smith R, Christophe A, Cosyns P, Desnyder R, Meltzer H. Fatty acid composition in major depression: decreased omega 3 fractions in cholesteryl esters and increased C20:4 omega 6/C20:5 omega 3 ratio in cholesteryl esters and phospholipids. J Affect Disord 1996; 38: 35-46.

[65] Maes M, Smith R, Christophe A, et al. Lower serum high-density lipoprotein cholesterol (HDL-C) in major depression and in depressed men with serious suicidal attempts: relationship with immune-inflammatory markers. Acta Psychiatr Scand 1997; 95: 212-21.

[66] Kiecolt-Glaser JK, Belury MA, Porter K, Beversdorf DQ, Lemeshow S, Glaser R. Depressive symptoms, omega-6:omega-3 fatty acids, and inflammation in older adults. Psychosom Med 2007; 69(3): 217-24.
[67] Orel M, Lichnovska R, Gwozdziewiczova S, et al. Gender differences in tumor necrosis factor-alpha and leptin secretion from subcutaneous and visceral fat tissue. Physiol Res 2004; 53: 501-5.

[68] Chiuve SE, Korngold EC, Januzzi JL Jr., Gantzer ML, Albert CM. Plasma and dietary magnesium and risk of sudden cardiac death in women. Am J Clin Nutr 2011; 93(2): 253-60.

[69] Sergey C, Agarval R, Singh RB, Wilczynska A, De Meester F. Can environmental factors predispose non-communicable diseases? Open Nutr J 2011; 4: 45-51.

[70] De Meester F. Progress in lipid nutrition. In: Simopoulos AP, De Meester F, Eds. A balanced omega-6/omega-3 fatty acid ratio. cholesterol and coronary heart disease. World Rev Nutr Diet, Basel: Karger 2009; vol. 100: pp. 110-12.

[71] Yang Y, Lu N, Chen D, Meng L, Zheng Y, Hui R. Effects of n-3 PUFA supplementation on plasma soluble adhesion molecules: a meta-analysis of randomized controlled trials. Am J Clin Nutr 2012; 95(4): 972-80.

[72] Singh RB, Fadecko J, Pellad D, De Meester F, Moshiri M, Aroussy WE. Superfood dietary approaches for acute myocardial infarction. World Heart J 2010; 2: 13-23.

[73] Wahle KW, Caruso D, Ochoa JJ, Quiles JL. Olive oil and modulation of cell signaling in disease prevention. Lipids 2004; 39 : 1223-31.

[74] Ghanim H, Sia CL, Upadhyay M, et al. Orange juice neutralizes the proinflammatory effect of a high-fat, high-carbohydrate meal and prevents endotoxin increase and Toll-like receptor expression. Am J Clin Nutr 2010; 91(4): 940-9.

Received: April 27, 2012

Revised: May 03, 2012

Accepted: May 03, 2012

(C) Fedacko et al.; Licensee Bentham Open.

This is an open access article licensed under the terms of the Creative Commons Attribution Non-Commercial License (http://creativecommons. org/licenses/ by-nc/3. 0/) which permits unrestricted, non-commercial use, distribution and reproduction in any medium, provided the work is properly cited. 